\title{
Associations of BRAP polymorphisms with the risk of alcohol dependence and scores on the Alcohol Use Disorders Identification Test
}

This article was published in the following Dove Press journal: Neuropsychiatric Disease and Treatment

\author{
Jee Wook Kim ${ }^{1,2}$ \\ Young Min Choe ${ }^{1,2}$ \\ Joong-Gon Shin ${ }^{3}$ \\ Byung Lae Park ${ }^{4}$ \\ Hyung-Doo Shin ${ }^{3,4}$ \\ Ihn-Geun Choi ${ }^{2,5}$ \\ Boung Chul Lee 2,6 \\ 'Department of Neuropsychiatry, \\ Hallym University Dongtan \\ Sacred Heart Hospital, Hwaseong, \\ Gyeonggi Province, Republic of \\ Korea; ${ }^{2}$ Department of Psychiatry, \\ Hallym University College of \\ Medicine, Chuncheon, Republic of \\ Korea; ${ }^{3}$ Department of Life Science, \\ Sogang University, Seoul, Republic \\ of Korea; ${ }^{4}$ Department of Genetic \\ Epidemiology, SNP Genetics, Inc., \\ Seoul, Republic of Korea; ${ }^{5}$ Department \\ of Neuropsychiatry, Hallym University \\ Kangnam Sacred Heart Hospital, \\ Seoul, Republic of Korea; ${ }^{6}$ Department \\ of Neuropsychiatry, Hallym University \\ Hangang Sacred Heart Hospital, Seoul, \\ Republic of Korea
}

Background: Alcohol dependence (AD) is a common disorder that is influenced by genetic as well as environmental factors. A previous genome-wide association study (GWAS) of the Korean population performed by our research group identified a number of genes, including BRCA1-associated protein (BRAP) and protein arginine methyltransferase 8 (PRMT8), as novel genetic markers of AD.

Methods: The present investigation was a fine-mapping follow-up study of $459 \mathrm{AD}$ and 455 non-AD subjects of Korean descent to determine the associations between BRAP and PRMT8 polymorphisms and AD. The Alcohol Use Disorders Identification Test (AUDIT) was administered to screen for the degree of $\mathrm{AD}$ risk in the subjects and 58 genetic variants, 5 for BRAP and 53 for PRMT8, were genotyped for subsequent association analyses.

Results: In the present case-control analysis, BRAP rs3782886 showed the most significant association signal with a risk of $\mathrm{AD}\left(P=1.29 \times 10^{-16}, P_{\text {corr }}=7.74 \times 10^{-16}, \mathrm{OR}=0.19\right)$. There were also significant differences in the overall and subcategory scores for the $B R A P$ genetic variants, including $r s 3782886\left(P=9.94 \times 10^{-31}, P_{\text {corr }}=5.96 \times 10^{-30}\right.$ at $r s 3782886$ for the overall AUDIT score $)$. However, the genetic effects of $P R M T 8$ polymorphisms observed in our previous GWAS were not replicated in the present study (minimum $P=0.0005, P_{\text {corr }}>0.05, \mathrm{OR}=0.30$ at $r s 4766139$ in the recessive model). Furthermore, the single-nucleotide polymorphisms of PRMT8 were not associated with the overall and subcategory AUDIT scores.

Conclusion: The present findings suggest that the genetic variants of BRAP may contribute to a predisposition for an alcohol use disorder.

Keywords: alcohol dependence, AUDIT, genome-wide association study, single-nucleotide polymorphism, BRAP

\section{Introduction}

Alcohol dependence (AD) is a severe psychiatric disorder with a multifactorial etiology that includes complex gene-to-gene and gene-to-environment interactions. ${ }^{1-3}$ Adoption and twin studies conducted to clarify the effects of genes in this etiology have revealed that genetic factors comprise $50 \%-60 \%$ of the heritability of AD susceptibility. 4,5 Additionally, adoptees are more similar to their biologic parents than their adoptive parents in terms of AD susceptibility ${ }^{6,7}$ and the higher concordance for AD susceptibility between twins is derived from shared genetic components. ${ }^{8}$ In fact, several candidate studies assessing the risk loci for AD were designed to target gene variants related to alcohol metabolism or neurobiology..$^{9-13}$

Recently, a number of genome-wide association studies (GWASs) have investigated genetic markers of $\mathrm{AD}$, including the genomic region of chromosome
Correspondence: Boung Chul Lee Department of Neuropsychiatry, Hallym University Hangang Sacred Heart Hospital, 12, Beodeunaru-ro 7-gil, Yeongdeungpo-gu, Seoul 07247, Republic of Korea

Tel +82226395460

Fax +82 226337571

Email woldyfig@me.com
Neuropsychiatric Disease and Treatment 2019:15 83-94

83

(c) (1) (2) ๑ 2019 kim et al. This work is published and licensed by Dove Medical Press Limited. The full terms of this license are available at https://www.dovepress.com/terms.php cc. hereby accept the Terms. Non-commercial uses of the work are permitted without any further permission from Dove Medical Press Limited, provided the work is properly attributed. For permision for commercial use of this work, please see paragraphs 4.2 and 5 of our Terms (https://www.dovepress.com/terms.php). 
4q22-q32, which includes alcohol dehydrogenase $(A D H)$ cluster genes. ${ }^{14-17}$ Furthermore, a recent GWAS of a Korean $\mathrm{AD}$ cohort revealed that three chromosomal regions are associated with $\mathrm{AD}$, including the $A D H$ gene cluster and $A L D H 2$, which participate in alcohol metabolism (minimum $P=6.46 \times 10^{-8}, \mathrm{OR}=2.73$ at $A D H 7 r s 10516441$ of the $A D H$ gene cluster and $P=8.42 \times 10^{-8}, \mathrm{OR}=0.22$ at $A L D H 2$ rs 671 ). The genetic effects of the $A D H$ gene cluster were also replicated in a Korean population (minimum $P=2.63 \times 10^{-21}$ at ADH1B rs 1229984). In addition to genes related to alcohol metabolism, genes known to participate in neurodevelopment, such as BRCA1-associated protein (BRAP) and protein arginine methyltransferase $8(P R M T 8)$, have multiple association signals with the risk of $\mathrm{AD}\left(P=4.65 \times 10^{-6}, \mathrm{OR}=0.31\right.$ at $B R A P$ rs 3782886 and $P=1.77 \times 10^{-5}, \mathrm{OR}=1.96$ at $P R M T 8$ $\left.r_{s} 876594\right) .{ }^{18}$ Based on the polygenic hypothesis of $\mathrm{AD}$ pathophysiology, it is possible that multiple genetic loci associated with neurobiologic pathways could be associated with the risk of AD. Thus, the present investigation conducted followup replication studies of our previous GWAS of a Korean cohort with $\mathrm{AD}$ to identify associations between the risk of $\mathrm{AD}$ and novel candidate genes other than those related to alcohol metabolism.

\section{Methods}

\section{Subject recruitment and the Alcohol Use Disorders Identification Test (AUDIT)}

The present study recruited 914 individuals of Korean descent from Hangang Sacred Heart, Keyo, Dasarang, KARF, and Humanity and Youth Rehabilitation Hospitals. Of these individuals, 459 were alcoholic subjects and 455 were nonalcoholic subjects; the nonalcoholic subjects were recruited from the industrial medical center of Hangang Sacred Heart Hospital. All subjects enrolled in this study underwent inpatient therapy for $>30$ days due to their drinking problems and the patients who comprised a subgroup in our previous study did not have major medical or comorbid psychiatric illnesses other than an alcohol-related disorder. ${ }^{11,19} \mathrm{AD}$ was diagnosed clinically with a semi-structured interview based on the guidelines of the Diagnostic and Statistical Manual of Mental Disorders IV $^{20}$ by skilled psychiatrists as well as on information provided by their caregivers; diagnostic validity was high because all subjects were hospitalized in alcohol-related hospitals. Most of the healthy controls were nondrinkers, although some were occasional light drinkers as revealed by a drinking habit questionnaire. Subjects who had first-degree relatives with major psychiatric disorders, including schizophrenia, mood disorders, and/or substance abuse disorders other than nicotine dependence, were excluded from the present analyses. The study protocol was approved by the institutional review board of each hospital. All participants provided written informed consent, and that this study was conducted in accordance with the Declaration of Helsinki.

The AUDIT was administered to screen for the degree of AD risk in the subjects. ${ }^{21}$ The AUDIT consists of ten items and is often used in Asian populations, including the Korean population. This tool includes three domain structures: items 1-3 measure alcohol consumption, items 4-6 assess AD, and items $7-10$ evaluate alcohol-related harm. ${ }^{22,23}$ All items are equally weighted, the scores range from 0 to 4 , and the total AUDIT score is determined by summing all subcategory scores; a higher AUDIT score is indicative of a higher risk in each category.

\section{Genotyping of the BRAP and PRMT8 polymorphisms}

To assess genomic DNA precisely, a DNA quantification analysis was performed using Quanti-iT PicoGreen fluorescence dye (Molecular Probes, Eugene, OR, USA). The quantification reactions were performed according to the manufacturer's instructions (Manual No: MP0758) and the concentration of each type of genomic DNA was measured with a Fluorescence Reader (VICTOR2 fluorometer; Perkin Elmer, CA, USA). Candidate single-nucleotide polymorphisms (SNPs) of BRAP and PRMT8 were selected from among Japanese and Han Chinese genotype data using the 1,000 Genomes database (http://browser.1000genomes.org/ index.html) based on the following conditions: 1) minor allele frequency (MAF) $>5 \%$; 2 ) linkage disequilibrium (LD) status based on an LD coefficient $\left(r^{2}\right)>0.98$; 3 ) positions within the gene; and 4) amino acid changes. A total of 58 SNPs ( 5 from BRAP and 53 from PRMT8) were genotyped in the 459 alcoholic subjects and 455 nonalcoholic subjects using the Illumina Golden Gate genotyping system at a multiplex level. ${ }^{24}$ The genotyping quality score for retaining data was set to 0.25 and SNPs that did not satisfy the following criteria were excluded: 1) a minimum call rate of $95 \%$ and 2) no duplicate errors.

\section{Statistical analysis}

The LD was obtained using Haploview v4.2 software (http:// www.broadinstitute.org/mpg/haploview) based on assessments of Lewontin's $\mathrm{D}^{\prime}\left(\left|D^{\prime}\right|\right)$ and the $r^{2}$ between all pairs of biallelic loci. ${ }^{25}$ Haplotypes were determined using PHASE v2.0 software ${ }^{26}$ and comparisons of the genotype distributions between alcoholic and nonalcoholic subjects were carried out with a logistic regression model adjusted for age (continuous value) and $\operatorname{sex}($ male $=0$, female $=1$ ) using SAS, 
version 9.4 (SAS Institute Inc., Cary, NC, USA). Associations between SNPs and AUDIT scores were also calculated using a linear regression model adjusted for age and sex. Statistical power of single associations was calculated using the Power for Genetic Association Analyses software, ${ }^{27}$ with false positive rate of $5 \%$, disease prevalence of $4 \%,{ }^{28}$ given MAFs and sample sizes, and assuming a relative risk of 1.5 . Corrected $P$-values for multiple testing were calculated using the Bonferroni correction method.

\section{Results}

The present study included a total of 914 subjects who were categorized as either $\operatorname{AD}(n=459$, mean age $=47.37$ years, range $=21-80$ years, 410 males and 49 females) or non-AD $(\mathrm{n}=455$, mean age $=44.21$ years, range $=20-79$ years, 351 males and 104 females; Table 1); there were no significant differences between the $\mathrm{AD}$ and non-AD subjects in terms of age or sex. The degree of AD risk was estimated using AUDIT scores.

\section{Genotyping and haplotype analyses of BRAP and PRMT8 SNPs}

A total of 58 SNPs ( 5 from BRAP and 53 from PRMT8) were genotyped in all subjects. The position, LD, and haplotype information of the investigated SNPs are shown in Figure S1. The BRAP and PRMT8 polymorphisms investigated in the present study were parsed into 1 LD block and 11 LD blocks, respectively. Not all haplotypes were selected for subsequent analyses because some haplotypes were tagged by SNPs on each gene.

\section{Association analyses of $B R A P$ and PRMT8 SNPs with AD}

Logistic regression analyses were conducted to investigate the associations between BRAP and PRMT8 genetic variants and the risk of $\mathrm{AD}$. In the case-control analysis, three genetic variants of BRAP (rs847895, rs3782886, and $r s 3803171)$ were associated with the risk of $\mathrm{AD}$ (minimum $P=1.29 \times 10^{-16}, \mathrm{OR}=0.19$ at $r s 3782886$ ) under the codominant model (Table 2). Of the PRMT8 SNPs, one genetic variant (rs 12581829) was marginally associated with the risk of $\mathrm{AD}$ under the codominant model $(P=0.02, \mathrm{OR}=0.72)$ and two SNPs (rs4766138 and rs4766139) showed nominal associations with the risk of $\mathrm{AD}$ under the recessive model $(P=0.002, \mathrm{OR}=0.33$ and $P=0.0005, \mathrm{OR}=0.30$, respectively; Table S1). However, the statistical significance of the PRMT8 SNPs disappeared after corrections for multiple analyses were performed.

\section{Associations of BRAP and PRMT8 SNPs with the degree of $A D$ risk}

To screen for the degree of risk of AD, additional association analyses between the AUDIT score and genetic variants of $B R A P$ or PRMT8 that showed associations with the risk of AD were conducted. For BRAP, three SNPs (rs3803171, rs3782886, and rs847895) and one haplotype (ht1) were significantly associated with the overall AUDIT score (minimum $P=9.94 \times 10^{-31}$ and minimum $P_{\text {corr }}=5.96 \times 10^{-30}$ at $r s 3782886$ ) and three SNPs had significant association signals with alcohol use disorders (minimum $P=3.30 \times 10^{-46}$ and $P_{\text {corr }}=1.98 \times 10^{-45}$ at $r s 3782886$ for alcohol consumption, minimum $P=1.95 \times 10^{-17}$ and $P_{\text {corr }}=1.17 \times 10^{-16}$ at $r s 3782886$ for AD, and minimum $P=3.89 \times 10^{-22}$ and $P_{\text {corr }}=2.34 \times 10^{-21}$ at rs3782886 for alcohol-related harm) based on the AUDIT scoring (Table 3 ). The strengths of the associations between the $B R A P$ SNPs and alcohol use disorders were greater in non-AD subjects. Additionally, BRAP rs3782886 was strongly associated with the overall AUDIT score $\left(P=1.40 \times 10^{-24}\right.$ and $\left.P_{\text {corr }}=8.39 \times 10^{-24}\right)$ and the subcategories of the AUDIT $\left(P=6.46 \times 10^{-32}\right.$ and $P_{\text {corr }}=3.87 \times 10^{-31}$ for alcohol consumption, $P=2.59 \times 10^{-7}$ and $P_{\text {corr }}=1.56 \times 10^{-6}$ for AD, and $P=3.88 \times 10^{-10}$, and $P_{\text {corr }}=2.32 \times 10^{-9}$ for alcohol-related harm; Table 4).

The association analysis of the PRMT8 SNPs revealed that individuals with three SNPs (rs4766138, rs4766139,

Table I Clinical profiles of study subjects

\begin{tabular}{|c|c|c|c|}
\hline Description & AD & Non-AD & $P$-value \\
\hline $\mathrm{N}$ & 459 & 455 & \\
\hline Age (year; mean-range) & $47.37(21-80)$ & $44.21(20-79)$ & $<0.00 I^{\mathrm{a}}$ \\
\hline Gender (M/F) & $410 / 49$ & $351 / 104$ & $<0.00 \mathrm{I}^{\mathrm{b}}$ \\
\hline \multicolumn{4}{|l|}{ AUDIT } \\
\hline Overall & $27.90 \pm 7.39(0-40)$ & $8.58 \pm 6.36(0-29)$ & $<0.00 I^{\mathrm{a}}$ \\
\hline Alcohol consumption & $10.23 \pm 2.10(0-12)$ & $5.73 \pm 3.46(0-12)$ & $<0.00 I^{a}$ \\
\hline Alcohol dependence & $7.37 \pm 3.26(0-12)$ & $0.99 \pm 1.50(0-8)$ & $<0.00 I^{a}$ \\
\hline Alcohol-related harm & $10.29 \pm 3.54(0-16)$ & $1.85 \pm 2.58(0-14)$ & $<0.00 I^{\mathrm{a}}$ \\
\hline
\end{tabular}

Notes: ${ }^{a} P$-value was calculated using $t$-test analysis. ${ }^{b} P$-value was calculated using chi-square analysis.

Abbreviations: AD, alcohol dependence; AUDIT, Alcohol Use Disorders Identification Test; F, female; M, male. 


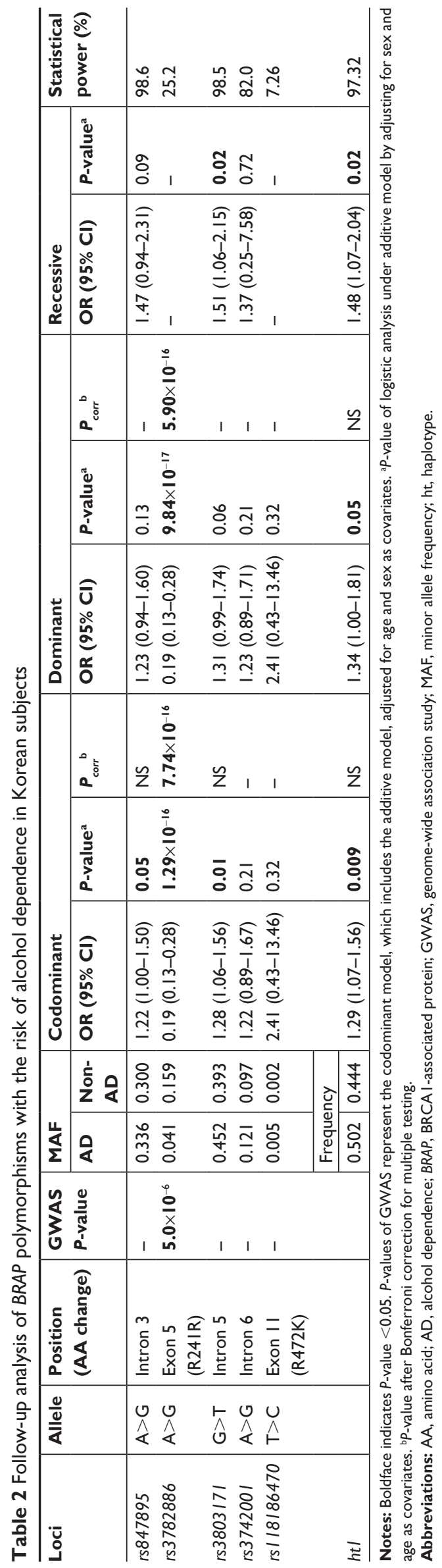

and $r s 12581829)$ showed a marginal association signal with the overall AUDIT score $(P=0.01,0.01$, and 0.008 , respectively; Table S2). However, the statistical significance of these associations disappeared after corrections for multiple analyses were performed.

\section{Discussion}

$\mathrm{AD}$ is a distressing chronic disease that results in significant human, social, and economic burdens. ${ }^{29}$ Drinking alcohol influences brain function by affecting brain tissues, brain cells, and the central nervous system (CNS). Accordingly, excessive alcohol consumption may result in severe deficits in cognition and memory function that are highly correlated with activity in nerve pathways. ${ }^{30}$ In a previous GWAS from our research group, ${ }^{18}$ BRAP and PRMT8 affected neurodevelopment in brain regions that were identified as having potential susceptibility loci for $\mathrm{AD}\left(P=4.65 \times 10^{-6}\right.$ at $B R A P$ rs3782886 and $P=1.77 \times 10^{-5}$ at $P R M T 8$ rs876594). Thus, $B R A P$ and $P R M T 8$ were proposed as novel candidate genes for controlling the amount of alcohol consumption.

$B R A P$ is a regulatory protein that binds to several translocation signal proteins in the cytoplasm ${ }^{31}$ and, based on its functions, can modulate several intracellular signaling pathways. First, $B R A P$ regulates the mitogen-activated protein kinase (MAPK) signaling pathway during CNS development through its function as a ubiquitin ligase. ${ }^{32}$ MAPK signaling is a known regulator of cell survival, proliferation, and differentiation as well as the production of proinflammatory cytokines. It has also been suggested that activation of the MAPK signaling pathway contributes to the neurotropic factor-mediated regulation of alcohol consumption..$^{33}$ Second, $B R A P$ acts as a primary mediator of inflammatory cascades by regulating the nuclear translocation of nuclear factor kappa $B$ $(\mathrm{NF}-\mathrm{kB}){ }^{34,35} \mathrm{~A}$ postmortem study in humans showed that $\mathrm{NF}-\kappa \mathrm{B}$ is downregulated in the brains of alcoholic patients. ${ }^{36}$ Similarly, other studies have shown that $B R A P$ silencing via RNA interference inhibits NF- $\kappa \mathrm{B}$ activation and that $B R A P$ expression is $\sim$ twofold higher due to the genetic variant rs11066001, which is a tagging SNP of $r s 3782886$ that has a high correlation value $\left(r^{2}=0.81\right) .{ }^{31,37,38}$ Taken together, these findings suggest that changes in $B R A P$ expression induced by genetic variants might affect the NF- $\mathrm{KB}$ inflammatory cascade and may be a mechanism by which $B R A P$ affects the risk level of $\mathrm{AD}$. However, the direct and/or indirect functional impacts of $B R A P$ on $\mathrm{AD}$ remain to be tested because the direct functional impacts of $B R A P$ on several human disorders, including schizophrenia, ${ }^{31}$ myocardial infarction, ${ }^{39}$ carotid atherosclerosis, ${ }^{37}$ and metabolic syndrome, ${ }^{40}$ are not yet fully understood. However, the function of $B R A P$ as a 
Table 3 Association analysis of BRAP polymorphisms with the AUDIT and subcategorical scores in all study subjects ( $\mathrm{n}=9 \mid 4)$

\begin{tabular}{|c|c|c|c|c|c|c|c|c|c|}
\hline \multirow[t]{2}{*}{ Category } & \multirow[t]{2}{*}{ Loci } & \multicolumn{2}{|l|}{$\mathrm{C} / \mathrm{C}$} & \multicolumn{2}{|c|}{$\mathbf{C} / \mathbf{R}$} & \multicolumn{2}{|c|}{$\mathbf{R} / \mathbf{R}$} & \multirow[t]{2}{*}{$P$-value ${ }^{a}$} & \multirow{2}{*}{$P_{\text {corr }}{ }^{b}$} \\
\hline & & $\mathbf{N}$ & AUDIT score & $\mathbf{N}$ & AUDIT score & $\mathbf{N}$ & AUDIT score & & \\
\hline \multirow[t]{4}{*}{ AUDIT all } & rs847895 & 424 & $17.46 \pm 11.96$ & 399 & $|8.57 \pm||.9|$ & 91 & $20.85 \pm 10.96$ & 0.01 & NS \\
\hline & rs3782886 & 736 & $20.36 \pm 11.12$ & 173 & $9.94 \pm 11.08$ & 5 & $1.20 \pm 1.64$ & $9.94 \times 10^{-31}$ & $5.96 \times 10^{-30}$ \\
\hline & $r s 380317 \mid$ & 299 & $16.81 \pm 1 \mid .88$ & 455 & $18.46 \pm 12.14$ & 158 & $20.37 \pm 10.69$ & 0.002 & 0.01 \\
\hline & $h t l$ & 250 & $16.54 \pm 11.96$ & 463 & $18.43 \pm 12.20$ & 201 & $20.09 \pm|0.7|$ & 0.0007 & 0.004 \\
\hline \multirow{4}{*}{$\begin{array}{l}\text { Alcohol } \\
\text { consumption }\end{array}$} & rs847895 & 424 & $7.81 \pm 3.70$ & 399 & $8.02 \pm 3.68$ & 91 & $8.68 \pm 3.07$ & 0.06 & - \\
\hline & $r s 3782886$ & 736 & $8.73 \pm 3.15$ & 173 & $5.06 \pm 3.91$ & 5 & $0.40 \pm 0.55$ & $3.30 \times 10^{-46}$ & $1.98 \times 10^{-45}$ \\
\hline & $r s 3803171$ & 299 & $7.61 \pm 3.70$ & 455 & $8.00 \pm 3.77$ & 158 & $8.64 \pm 3.02$ & 0.005 & 0.02 \\
\hline & htl & 250 & $7.29 \pm 3.88$ & 463 & $7.98 \pm 3.73$ & 201 & $8.89 \pm 2.84$ & $3.36 \times 10^{-07}$ & $2.02 \times 10^{-6}$ \\
\hline \multirow{4}{*}{$\begin{array}{l}\text { Alcohol } \\
\text { dependence }\end{array}$} & rs847895 & 424 & $3.92 \pm 4.05$ & 399 & $4.36 \pm 4.13$ & 91 & $4.78 \pm 3.91$ & 0.02 & NS \\
\hline & $r s 3782886$ & 736 & $4.74 \pm 4.06$ & 173 & $2.01 \pm 3.35$ & 5 & $0.00 \pm 0.00$ & $1.95 \times 10^{-17}$ & $1.17 \times 10^{-16}$ \\
\hline & rs3803I7I & 299 & $3.75 \pm 4.04$ & 455 & $4.33 \pm 4.10$ & 158 & $4.57 \pm 3.97$ & 0.03 & NS \\
\hline & $h t l$ & 250 & $3.64 \pm 3.94$ & 463 & $4.34 \pm 4.14$ & 201 & $4.57 \pm 4.06$ & 0.009 & NS \\
\hline \multirow{4}{*}{$\begin{array}{l}\text { Alcohol-related } \\
\text { harm }\end{array}$} & rs847895 & 424 & $5.73 \pm 5.29$ & 399 & $6.18 \pm 5.16$ & 91 & $7.38 \pm 5.22$ & 0.007 & NS \\
\hline & rs3782886 & 736 & $6.88 \pm 5.10$ & 173 & $2.87 \pm 4.56$ & 5 & $0.80 \pm 1.79$ & $3.89 \times 10^{-22}$ & $2.34 \times 10^{-21}$ \\
\hline & rs3803I7I & 299 & $5.45 \pm 5.16$ & 455 & $6.12 \pm 5.29$ & 158 & $7.16 \pm 5.07$ & 0.001 & 0.007 \\
\hline & $h t l$ & 250 & $5.61 \pm 5.30$ & 463 & $6.12 \pm 5.31$ & 201 & $6.63 \pm 4.98$ & 0.03 & NS \\
\hline
\end{tabular}

Notes: $C / C, C / R$, and R/R mean major homozygote, heterozygote, and minor homozygote, respectively. AUDIT score is mean \pm SD. Boldface indicates $P$-value $<0.05$. a $P$-value of linear regression analysis under additive model by adjusting for sex and age as covariates. ${ }^{b} P$-value after Bonferroni correction for multiple testing. Abbreviations: AUDIT, Alcohol Use Disorders Identification Test; BRAP, BRCAI-associated protein; ht, haplotype; NS, not significant.

mediator of the translocation of signaling proteins might be a plausible explanation for the association between $B R A P$ and human diseases with distinct pathophysiologies. Taken together, these data support the notion that BRAP has a genetic effect on alcohol-related disorders via the control of various signaling pathways.
PRMT8 is a member of the arginine methyltransferase gene family that influences several cellular processes, such as DNA repair, RNA transcription, and signal transduction, by methylating target regions. ${ }^{41}$ Of this protein family, only PRMT8 has an expression that is highly restricted to the CNS. ${ }^{42}$ Several studies have reported that arginine

Table 4 Association analysis of BRAP polymorphisms with the AUDIT and subcategorical scores in non-alcohol dependence subjects $(n=455)$

\begin{tabular}{|c|c|c|c|c|c|c|c|c|c|}
\hline \multirow[t]{2}{*}{ Category } & \multirow[t]{2}{*}{ Loci } & \multicolumn{2}{|l|}{$\mathrm{C} / \mathrm{C}$} & \multicolumn{2}{|l|}{ C/R } & \multicolumn{2}{|c|}{$\mathbf{R} / \mathbf{R}$} & \multirow[t]{2}{*}{$P$-value ${ }^{a}$} & \multirow[t]{2}{*}{$P_{\text {corr }}{ }^{b}$} \\
\hline & & $\mathbf{N}$ & $\begin{array}{l}\text { AUDIT } \\
\text { score }\end{array}$ & $\mathbf{N}$ & $\begin{array}{l}\text { AUDIT } \\
\text { score }\end{array}$ & $\mathbf{N}$ & $\begin{array}{l}\text { AUDIT } \\
\text { score }\end{array}$ & & \\
\hline \multirow[t]{4}{*}{ AUDIT all } & rs847895 & 221 & $7.91 \pm 5.92$ & 195 & $9.00 \pm 6.83$ & 39 & $10.21 \pm 6.01$ & 0.007 & 0.04 \\
\hline & rs3782886 & 315 & $10.26 \pm 6.23$ & 135 & $4.91 \pm 4.88$ & 5 & $1.20 \pm 1.64$ & $1.40 \times 10^{-24}$ & $8.39 \times 10^{-24}$ \\
\hline & rs380317I & 163 & $7.87 \pm 5.94$ & 226 & $8.62 \pm 6.65$ & 66 & $10.17 \pm 6.15$ & 0.004 & 0.02 \\
\hline & $h t l$ & 138 & $7.44 \pm 6.35$ & 230 & $8.52 \pm 6.47$ & 87 & $10.53 \pm 5.65$ & 0.0001 & 0.0006 \\
\hline Alcohol & $r s 847895$ & 221 & $5.57 \pm 3.43$ & 195 & $5.76 \pm 3.56$ & 39 & $6.49 \pm 3.05$ & 0.11 & - \\
\hline \multirow[t]{3}{*}{ consumption } & rs3782886 & 315 & $6.7 I \pm 3.20$ & 135 & $3.64 \pm 2.97$ & 5 & $0.40 \pm 0.55$ & $6.46 \times 10^{-32}$ & $3.87 \times 10^{-31}$ \\
\hline & $r s 380317 I$ & 163 & $5.49 \pm 3.37$ & 226 & $5.67 \pm 3.58$ & 66 & $6.53 \pm 3.17$ & 0.02 & NS \\
\hline & $h t l$ & 138 & $4.97 \pm 3.58$ & 230 & $5.61 \pm 3.42$ & 87 & $7.24 \pm 2.89$ & $1.02 \times 10^{-07}$ & $6.13 \times 10^{-7}$ \\
\hline Alcohol & rs847895 & 221 & $0.81 \pm 1.33$ & 195 & $1.14 \pm 1.62$ & 39 & $1.33 \pm 1.66$ & 0.006 & NS \\
\hline \multirow[t]{3}{*}{ dependence } & rs3782886 & 315 & $1.22 \pm 1.59$ & 135 & $0.50 \pm 1.11$ & 5 & $0.00 \pm 0.00$ & $2.59 \times 10^{-07}$ & $1.56 \times 10^{-6}$ \\
\hline & rs3803I7I & 163 & $0.75 \pm 1.22$ & 226 & $1.10 \pm 1.62$ & 66 & $1.24 \pm 1.6 \mathrm{I}$ & 0.004 & 0.02 \\
\hline & htl & 138 & $0.89 \pm 1.45$ & 230 & $1.06 \pm 1.60$ & 87 & $0.99 \pm 1.26$ & 0.58 & - \\
\hline Alcohol-related & rs847895 & 221 & $1.54 \pm 2.26$ & 195 & $2.10 \pm 2.87$ & 39 & $2.38 \pm 2.62$ & 0.008 & 0.04 \\
\hline \multirow[t]{3}{*}{ harm } & rs3782886 & 315 & $2.33 \pm 2.76$ & 135 & $0.77 \pm 1.7 \mid$ & 5 & $0.80 \pm 1.79$ & $3.88 \times 10^{-10}$ & $2.32 \times 10^{-9}$ \\
\hline & rs3803/7I & 163 & $1.63 \pm 2.38$ & 226 & $1.86 \pm 2.56$ & 66 & $2.39 \pm 3.04$ & 0.03 & NS \\
\hline & $h t l$ & 138 & $1.58 \pm 2.62$ & 230 & $1.85 \pm 2.53$ & 87 & $2.30 \pm 2.63$ & 0.04 & NS \\
\hline
\end{tabular}

Notes: $\mathrm{C} / \mathrm{C}, \mathrm{C} / \mathrm{R}$, and $\mathrm{R} / \mathrm{R}$ mean major homozygote, heterozygote, and minor homozygote, respectively. AUDIT score is mean $\pm \mathrm{SD}$. Boldface indicates $P$-value $<0.05$. ${ }^{\text {a }}$-value of linear regression analysis under additive model by adjusting for sex and age as covariates. ${ }^{b} P$-value after Bonferroni correction for multiple testing.

Abbreviations: AUDIT, Alcohol Use Disorders Identification Test; BRAP, BRCAI-associated protein; ht, haplotype; NS, not significant. 
methylation is important for neurogenesis, which is essential for neurologic function. ${ }^{41,43}$ Although PRMT8 genetic variants showed nominal association signals with the risk of AD, genetic variants of PRMT8 might be implicated in the neuronal differentiation in the brain region.

Interestingly, the strength of the association between $B R A P$ and alcohol use disorders was greater in nonalcoholic subjects than alcoholic subjects in the present study. $B R A P$ is located a short distance from, and is affected by, the concomitant activity of $A L D H 2$, which is highly related to AD. Thus, their association may be more prominent in nonalcoholic subjects because when $A L D H 2$ induces lower rates of ALDH2 catalytic activity, even a small amount of alcohol consumption can cause a dramatic enhancement in acetaldehyde levels that triggers a highly aversion reaction. Therefore, these subjects may be classified as nonalcoholics even though there is an association between $B R A P$ and alcohol use disorders. BRAP may also be a common gene associated with the characteristic patterns of alcohol use among nonalcoholic subjects. Taken together, these findings suggest that the effects of $B R A P$ in nonalcoholics are very complicated and, as a result, interpretations of the present results should be made cautiously.

Although some evidence supports an association between $B R A P$ and $\mathrm{AD}$, it is also important to discuss the independent effects of this gene. There are strong LD values between $B R A P$ rs 3782886 and $A L D H 2$ rs $671^{44}$ and it will be difficult to identify strong genetic influences on AD pathophysiology that arise from only a single or several genes. On the other hand, AD pathophysiology is associated with several unexplained effects from single or several genes, that is, the roles that $A D H$ and $A L D H 2$ play in alcohol metabolism. Despite the fact that these effects are relatively small, many genes with limited effects may be involved in the pathophysiology of AD. Based on the polygenic hypothesis of AD pathophysiology, it is possible that multiple genetic loci in genes related to neurobiologic pathways could be associated with the risk of AD. Although $B R A P$ has fewer independent effects in AD pathophysiology than $A L D H 2, B R A P$ may be involved in this process via the summation of many genes with small effects. The present findings suggest that BRAP may contribute to AD pathophysiology via contributions following the summation of its effects with the well-known effects of $A L D H 2$.

\section{Conclusion}

Based on findings from a GWAS and a replication study of a Korean AD cohort, the present study was the first to propose that a BRAP SNP (rs3782886) was associated with AD.
A future follow-up replication study using an independent sample may strengthen the present results and provide substantiation of the proposed polygenetic influences. Nevertheless, these novel findings provide important evidence that will contribute to the current understanding of the genetic etiology of AD as well as the development of assessments of $\mathrm{AD}$ risk that can be used in conjunction with conventional causal markers.

\section{Acknowledgments}

This study was supported by a grant from the Korea Healthcare Technology R\&D Project, Ministry for Health, Welfare and Family Affairs, Republic of Korea (grant number A084589) and a grant from Hallym University Research Fund 2015, Republic of Korea (HRF-2015-28). This paper was presented at the 16th World Congress of Psychiatry, Madrid, Spain, as an abstract presentation with interim findings on September 15, 2014.

\section{Disclosure}

Byung Lae Park is an employee and Hyung Doo Shin is the CEO of SNP Genetics, Inc., which is located at \#TE1007, Teilhard Hall, Sogang University, Shinsu-dong, Mapo-gu, Seoul, 121-742, Republic of Korea. This company provided the iScan scanner instrument and BeadStudio 3.0 software used in the research. They were also involved in the study design, data collection and analysis, decision to publish, and preparation of the manuscript. However, these competing interests did not alter the authors' adherence to all policies of Neuropsychiatric Disease and Treatment. The others authors report no conflicts of interest in this work.

\section{References}

1. Prom-Wormley EC, Ebejer J, Dick DM, Bowers MS. The genetic epidemiology of substance use disorder: a review. Drug Alcohol Depend. 2017;180:241-259.

2. Zollanvari A, Alterovitz G. SNP by SNP by environment interaction network of alcoholism. BMC Syst Biol. 2017;11(Suppl 3):19.

3. Gordis E. Genes and the environment in complex diseases: a focus on alcoholism. Mol Psychiatry. 1997;2(4):282-286.

4. Kendler KS, Heath AC, Neale MC, Kessler RC, Eaves LJ. A populationbased twin study of alcoholism in women. JAMA. 1992;268(14):1877-1882.

5. Prescott CA, Kendler KS. Genetic and environmental contributions to alcohol abuse and dependence in a population-based sample of male twins. Am J Psychiatry. 1999;156(1):34-40.

6. Bohman M, Sigvardsson S, Cloninger CR. Maternal inheritance of alcohol abuse. Cross-fostering analysis of adopted women. Arch Gen Psychiatry. 1981;38(9):965-969.

7. Sigvardsson S, Bohman M, Cloninger CR. Replication of the stockholm adoption study of alcoholism. Confirmatory cross-fostering analysis. Arch Gen Psychiatry. 1996;53(8):681-687.

8. Kendler KS, Neale MC, Heath AC, Kessler RC, Eaves LJ. A twinfamily study of alcoholism in women. Am J Psychiatry. 1994;151(5): 707-715. 
9. Choi IG, Son HG, Yang BH, et al. Scanning of genetic effects of alcohol metabolism gene (ADH1B and ADH1C) polymorphisms on the risk of alcoholism. Hum Mutat. 2005;26(3):224-234.

10. Edenberg HJ, Xuei X, Chen HJ, et al. Association of alcohol dehydrogenase genes with alcohol dependence: a comprehensive analysis. Hum Mol Genet. 2006;15(9):1539-1549.

11. Kim DJ, Choi IG, Park BL, et al. Major genetic components underlying alcoholism in Korean population. Hum Mol Genet. 2008;17(6): 854-858.

12. Samochowiec J, Samochowiec A, Puls I, Bienkowski P, Schott BH. Genetics of alcohol dependence: a review of clinical studies. Neuropsychobiology. 2014;70(2):77-94

13. Thompson MD, Kenna GA. Variation in the serotonin transporter gene and alcoholism: risk and response to pharmacotherapy. Alcohol Alcohol. 2016;51(2):164-171.

14. Bierut LJ, Agrawal A, Bucholz KK, et al; Gene, Environment Association Studies Consortium. A genome-wide association study of alcohol dependence. Proc Natl Acad Sci U S A. 2010;107(11):5082-5087.

15. Lind PA, Macgregor S, Vink JM, et al. A genomewide association study of nicotine and alcohol dependence in Australian and Dutch populations. Twin Res Hum Genet. 2010;13(1):10-29.

16. Zuo L, Zhang XY, Wang F, et al. Genome-wide significant association signals in IPO11-HTR1A region specific for alcohol and nicotine codependence. Alcohol Clin Exp Res. 2013;37(5):730-739.

17. Baik I, Cho NH, Kim SH, Han BG, Shin C. Genome-wide association studies identify genetic loci related to alcohol consumption in Korean men. Am J Clin Nutr. 2011;93(4):809-816.

18. Park BL, Kim JW, Cheong HS, et al. Extended genetic effects of ADH cluster genes on the risk of alcohol dependence: from GWAS to replication. Hum Genet. 2013;132(6):657-668.

19. Joe KH, Kim DJ, Park BL, et al. Genetic association of DRD2 polymorphisms with anxiety scores among alcohol-dependent patients. Biochem Biophys Res Commun. 2008;371(4):591-595.

20. American Psychiatric Association. American Psychiatric Association Task Force on DSM-IV. Diagnostic and Statistical Manual of Mental Disorders: DSM-IV. 4th ed. Washington, DC: American Psychiatric Association; 1994.

21. Saunders JB, Aasland OG, Babor TF, de la Fuente JR, Grant M. Development of the Alcohol Use Disorders Identification Test (AUDIT): WHO collaborative project on early detection of persons with harmful alcohol consumption - II. Addiction. 1993;88(6):791-804.

22. Sung J, Lee K, Song YM. Heritabilities of Alcohol Use Disorders Identification Test (AUDIT) scores and alcohol biomarkers in Koreans: the KoGES (Korean Genome Epi Study) and Healthy Twin Study. Drug Alcohol Depend. 2011;113(2-3):104-109.

23. Tsai MC, Tsai YF, Chen CY, Liu CY. Alcohol Use Disorders Identification Test (AUDIT): establishment of cut-off scores in a hospitalized Chinese population. Alcohol Clin Exp Res. 2005;29(1):53-57.

24. Oliphant A, Barker DL, Stuelpnagel JR, Chee MS. BeadArray technology: enabling an accurate, cost-effective approach to high-throughput genotyping. Biotechniques. 2002;(Supp1):S56-S61.

25. Barrett JC, Fry B, Maller J, Daly MJ. Haploview: analysis and visualization of LD and haplotype maps. Bioinformatics. 2005;21(2):263-265.

26. Stephens M, Smith NJ, Donnelly P. A new statistical method for haplotype reconstruction from population data. Am J Hum Genet. 2001; 68(4):978-989.
27. Menashe I, Rosenberg PS, Chen BE. PGA: power calculator for casecontrol genetic association analyses. BMC Genet. 2008;9:36.

28. Ezzati M, Lopez AD, Rodgers A, vander Hoorn S, Murray CJ; Comparative Risk Assessment Collaborating Group. Selected major risk factors and global and regional burden of disease. Lancet. 2002;360(9343): 1347-1360.

29. Collins PY, Patel V, Joestl SS, et al. Grand challenges in global mental health. Nature. 2011;475(7354):27-30.

30. Kim JW, Lee DY, Lee BC, et al. Alcohol and cognition in the elderly: a review. Psychiatry Investig. 2012;9(1):8-16.

31. Zhang F, Liu C, Xu Y, et al. A two-stage association study suggests BRAP as a susceptibility gene for schizophrenia. PLoS One. 2014;9(1): e86037.

32. Lanctot AA, Peng CY, Pawlisz AS, Joksimovic M, Feng Y. Spatially dependent dynamic MAPK modulation by the Nde1-Lis1-Brap complex patterns mammalian CNS. Dev Cell. 2013;25(3):241-255.

33. Jeanblanc J, Logrip ML, Janak PH, Ron D. BDNF-mediated regulation of ethanol consumption requires the activation of the MAP kinase pathway and protein synthesis. Eur J Neurosci. 2013;37(4):607-612.

34. Takashima O, Tsuruta F, Kigoshi Y, et al. Brap2 regulates tempora control of NF- $\mathrm{KB}$ localization mediated by inflammatory response. PLoS One. 2013;8(3):e58911.

35. Plestant $\mathrm{C}$, Anton ES. Scaling the MAPK signaling threshold during CNS patterning. Dev Cell. 2013;25(3):221-222.

36. Okvist A, Johansson S, Kuzmin A, et al. Neuroadaptations in human chronic alcoholics: dysregulation of the NF-kappaB system. PLoS One. 2007;2(9):e930.

37. Liao YC, Wang YS, Guo YC, et al. BRAP Activates inflammatory cascades and increases the risk for carotid atherosclerosis. $\mathrm{Mol} \mathrm{Med}$. 2011;17(9-10):1065-1074.

38. Tsai PC, Liao YC, Lin TH, Hsi E, Yang YH, Juo SH. Additive effect of ANRIL and BRAP polymorphisms on ankle-brachial index in a Taiwanese population. Circ J. 2012;76(2):446-452.

39. Ozaki K, Sato H, Inoue K, et al. SNPs in BRAP associated with risk of myocardial infarction in Asian populations. Nat Genet. 2009;41(3): 329-333.

40. Avery CL, He Q, North KE, et al. A phenomics-based strategy identifies loci on APOC1, BRAP, and PLCG1 associated with metabolic syndrome phenotype domains. PLoS Genet. 2011;7(10):e1002322.

41. Dillon MB, Rust HL, Thompson PR, Mowen KA. Automethylation of protein arginine methyltransferase 8 (PRMT8) regulates activity by impeding S-adenosylmethionine sensitivity. J Biol Chem. 2013; 288(39):27872-27880.

42. Lee J, Sayegh J, Daniel J, Clarke S, Bedford MT. PRMT8, a new membrane-bound tissue-specific member of the protein arginine methyltransferase family. J Biol Chem. 2005;280(38):32890-32896.

43. Kim S, Parks CG, Xu Z, et al. Association between genetic variants in DNA and histone methylation and telomere length. PLoS One. 2012; 7(7):e40504.

44. Kamatani Y, Matsuda K, Okada Y, et al. Genome-wide association study of hematological and biochemical traits in a Japanese population. Nat Genet. 2010;42:210-215. 


\section{Supplementary materials}

A

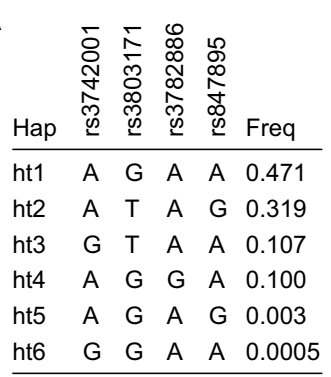

C

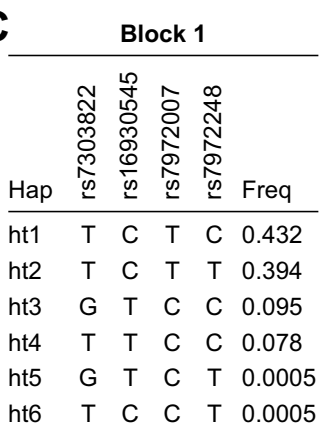

\begin{tabular}{|c|c|c|c|c|c|c|}
\hline \multicolumn{7}{|c|}{ Block 2} \\
\hline Hap & 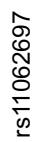 & 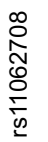 & 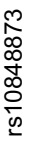 & 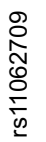 & 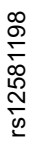 & Freq \\
\hline ht1 & C & A & A & $\mathrm{G}$ & G & 0.461 \\
\hline ht2 & A & A & A & G & A & 0.270 \\
\hline ht3 & C & A & A & A & A & 0.170 \\
\hline ht4 & C & $\mathrm{T}$ & G & $\mathrm{G}$ & G & 0.063 \\
\hline ht5 & $C$ & A & G & $G$ & G & 0.020 \\
\hline ht6 & $C$ & A & A & $\mathrm{G}$ & A & 0.009 \\
\hline ht7 & $C$ & A & A & $A$ & G & 0.003 \\
\hline ht8 & A & A & A & G & G & 0.002 \\
\hline ht9 & A & A & A & A & A & 0.002 \\
\hline
\end{tabular}
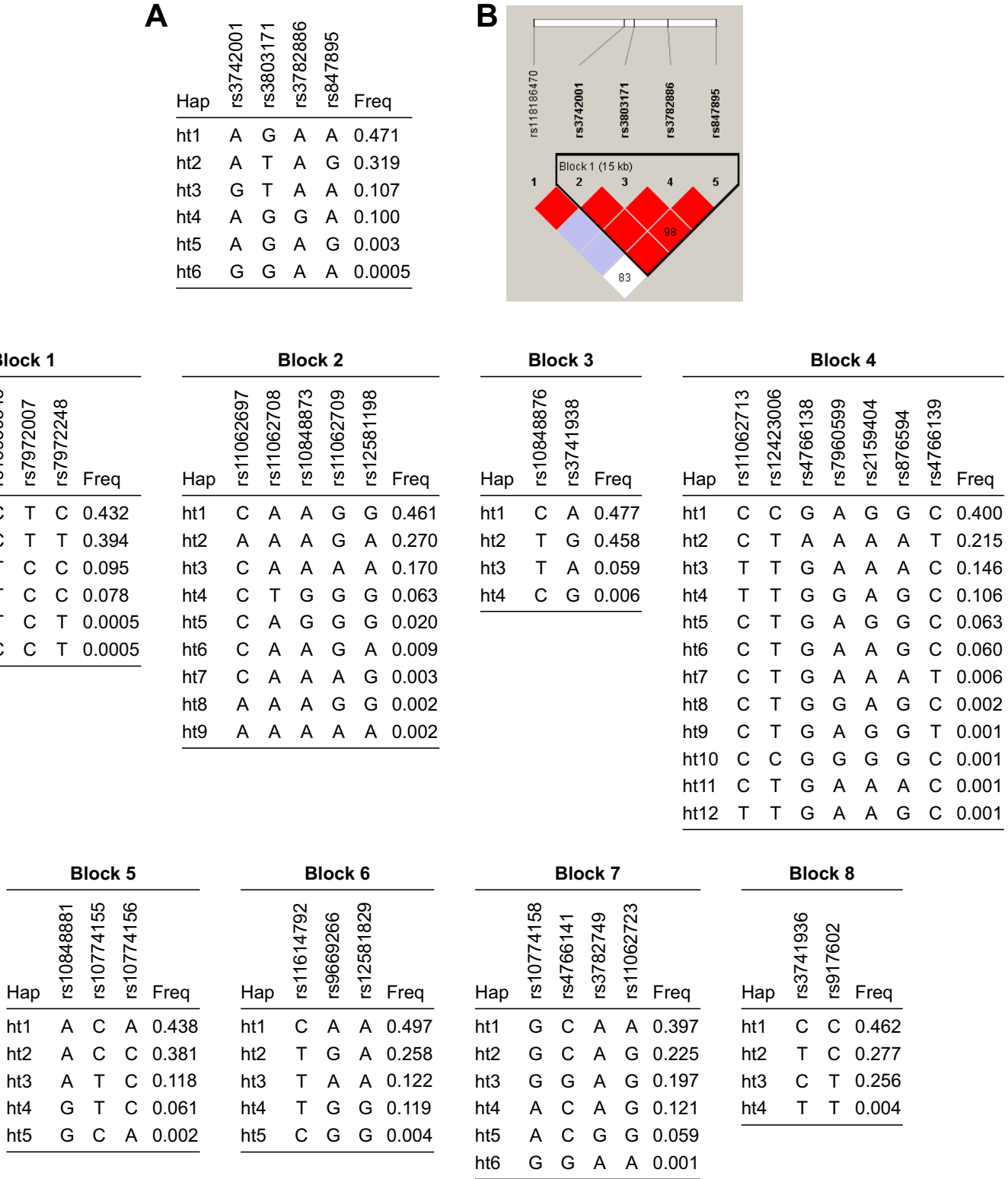

\begin{tabular}{|c|c|c|c|c|}
\hline \multicolumn{5}{|c|}{ Block 9} \\
\hline Hap & $\begin{array}{l}8 \\
8 \\
80 \\
\stackrel{0}{0} \\
\stackrel{0}{0}\end{array}$ & 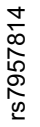 & 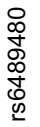 & Freq \\
\hline ht1 & $A$ & G & $A$ & 0.853 \\
\hline ht2 & G & $A$ & G & 0.111 \\
\hline ht3 & $\mathrm{G}$ & G & A & 0.034 \\
\hline ht4 & G & G & G & 0.001 \\
\hline ht5 & $A$ & $A$ & $A$ & 0.001 \\
\hline
\end{tabular}

\begin{tabular}{|c|c|c|c|c|c|c|c|c|}
\hline \multicolumn{9}{|c|}{ Block 10} \\
\hline$p$ & 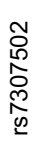 & 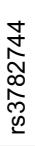 & $\begin{array}{l}\text { P } \\
\text { o } \\
0 \\
0 \\
\text { o } \\
\text { w }\end{array}$ & 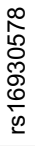 & $\begin{array}{l}\hat{\tilde{O}} \\
\stackrel{0}{0} \\
\stackrel{0}{0} \\
\stackrel{0}{\omega}\end{array}$ & 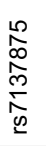 & $\begin{array}{l}\bar{\rho} \\
\stackrel{0}{0} \\
\stackrel{0}{0} \\
\frac{\Gamma}{\infty}\end{array}$ & Freq \\
\hline & $A$ & $T$ & $A$ & G & $C$ & A & $G$ & 0.4 \\
\hline & $A$ & C & $A$ & G & $T$ & A & G & 0.35 \\
\hline & G & C & G & A & $C$ & G & C & 0.08 \\
\hline & G & C & A & G & $\mathrm{T}$ & A & G & 0.03 \\
\hline & G & C & G & G & C & $\mathrm{G}$ & C & 0.03 \\
\hline & G & C & A & G & C & G & C & 0.02 \\
\hline & G & C & $A$ & G & C & G & G & 0.00 \\
\hline & A & C & $A$ & G & C & A & G & 0.0 \\
\hline & $G$ & $c$ & 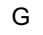 & $G$ & C & G & G & 0.002 \\
\hline & A & C & $G$ & $\checkmark$ & C & $\mathrm{G}$ & C & 0.00 \\
\hline
\end{tabular}

\begin{tabular}{|c|c|c|c|c|c|c|}
\hline \multicolumn{7}{|c|}{ Block 11} \\
\hline Hap & 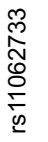 & 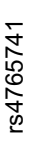 & 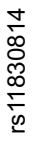 & 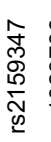 & 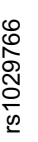 & Freq \\
\hline ht1 & C & A & G & G & C & 0.468 \\
\hline ht2 & C & G & G & G & $\mathrm{T}$ & 0.304 \\
\hline ht3 & C & G & G & A & T & 0.102 \\
\hline ht4 & $\mathrm{T}$ & G & $C$ & G & C & 0.080 \\
\hline ht5 & $\mathrm{T}$ & G & $\mathrm{G}$ & G & C & 0.022 \\
\hline ht6 & C & G & G & G & C & 0.020 \\
\hline ht7 & C & G & $\mathrm{G}$ & A & C & 0.003 \\
\hline ht8 & C & $A$ & $C$ & $G$ & C & 0.001 \\
\hline ht9 & C & A & G & G & $\mathrm{T}$ & 0.001 \\
\hline
\end{tabular}

Figure SI (Continued) 
D

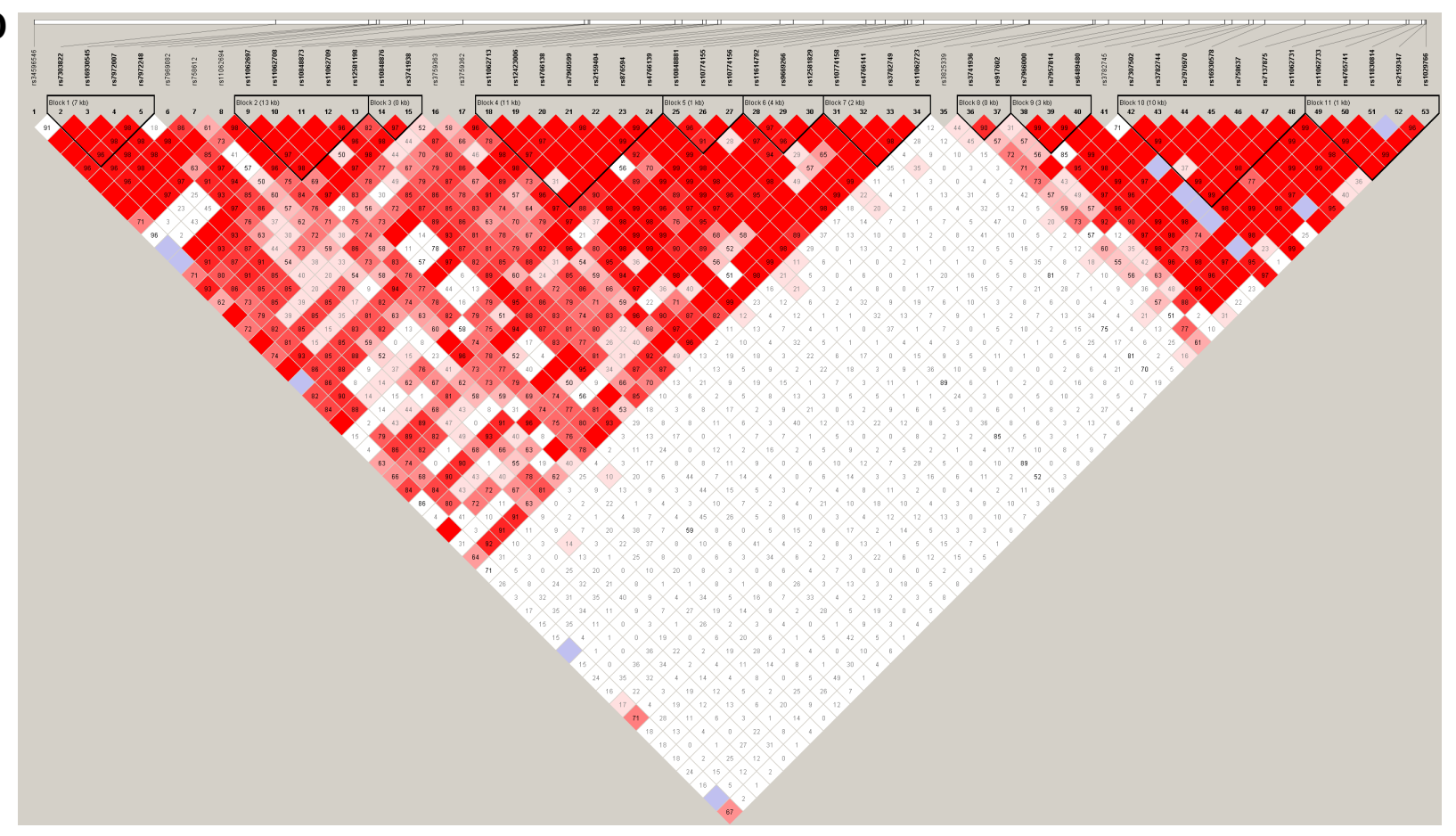

Figure SI Haplotypes and LD structures of BRAP and PRMT8.

Notes: (A) Haplotypes of and (B) LDs among BRAP polymorphisms. (C) Haplotypes of and (D) LDs among PRMT8 polymorphisms.

Abbreviations: BRAP, BRCAI-associated protein; LD, linkage disequilibrium; PRMT8, protein arginine methyltransferase. 


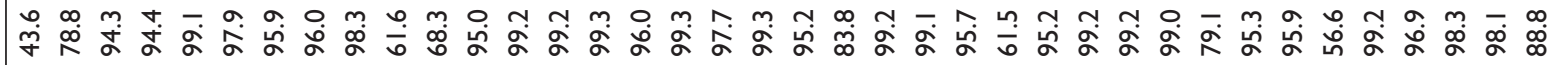

$\frac{4}{3}$

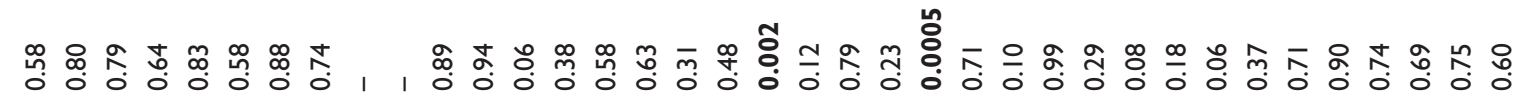

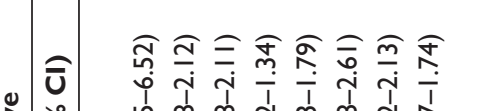

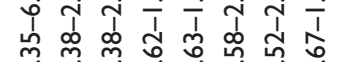

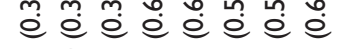

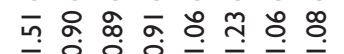

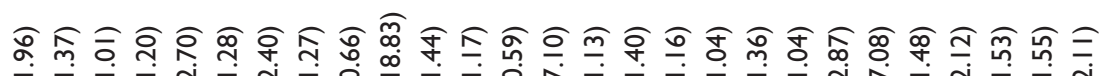
T.

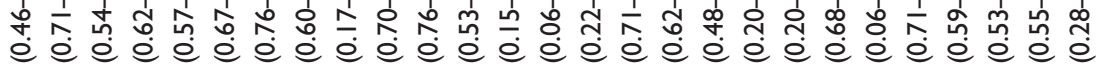

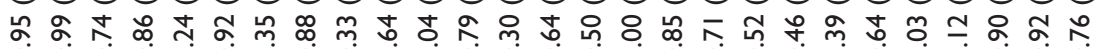

o.

$\stackrel{\frac{1}{3}}{\frac{9}{2}}$

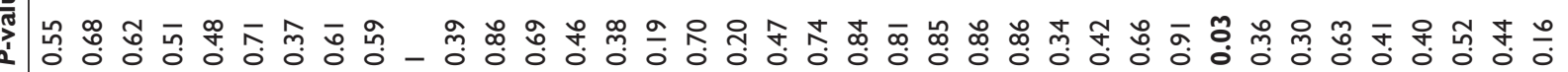

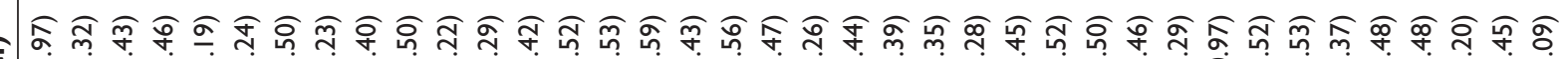

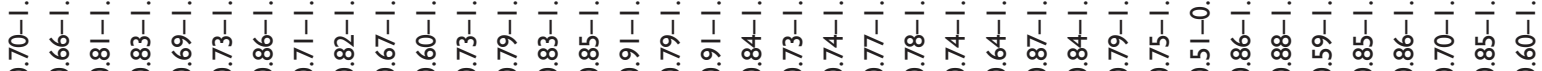

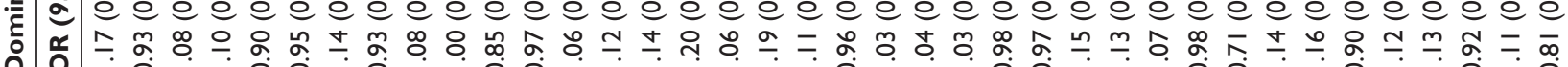

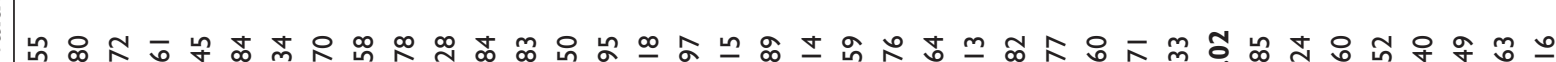

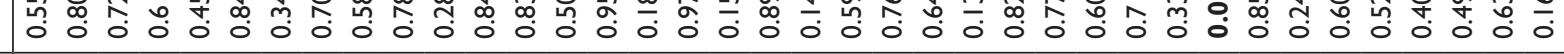

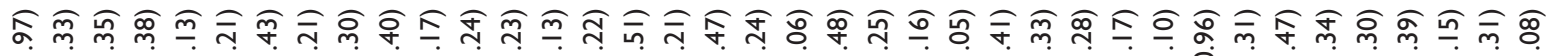

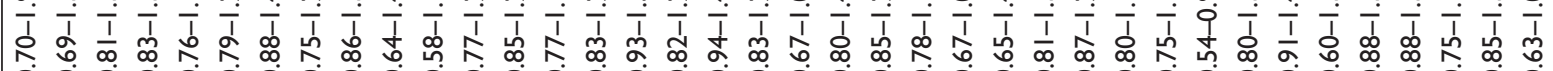

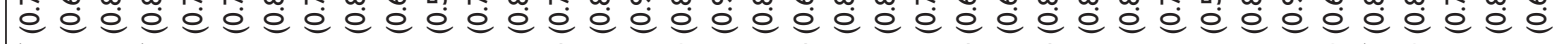

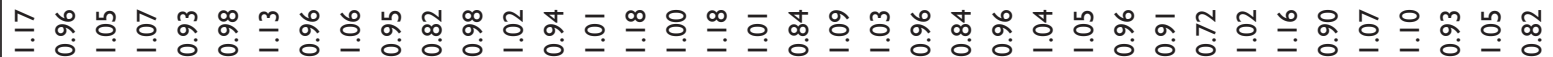

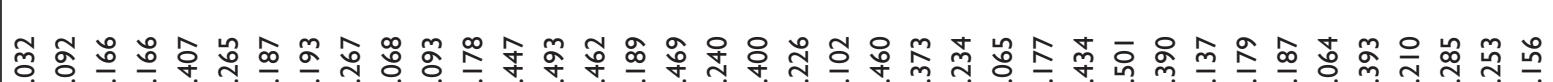

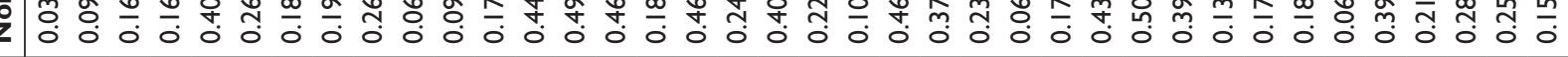

m

ชั

ั̊े

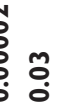

$\stackrel{\text { ڤn }}{\circ}$

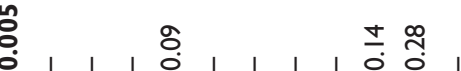

U U R U R

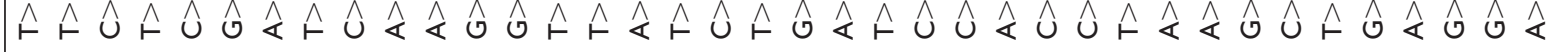

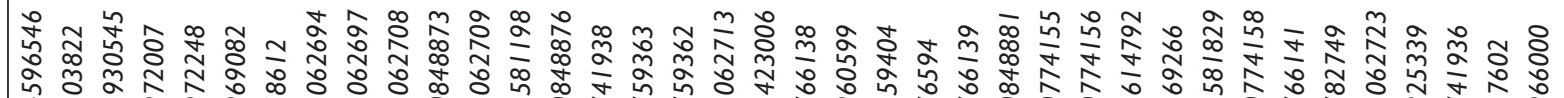

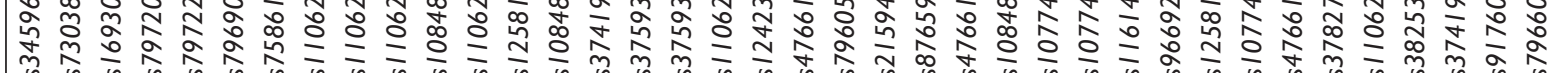




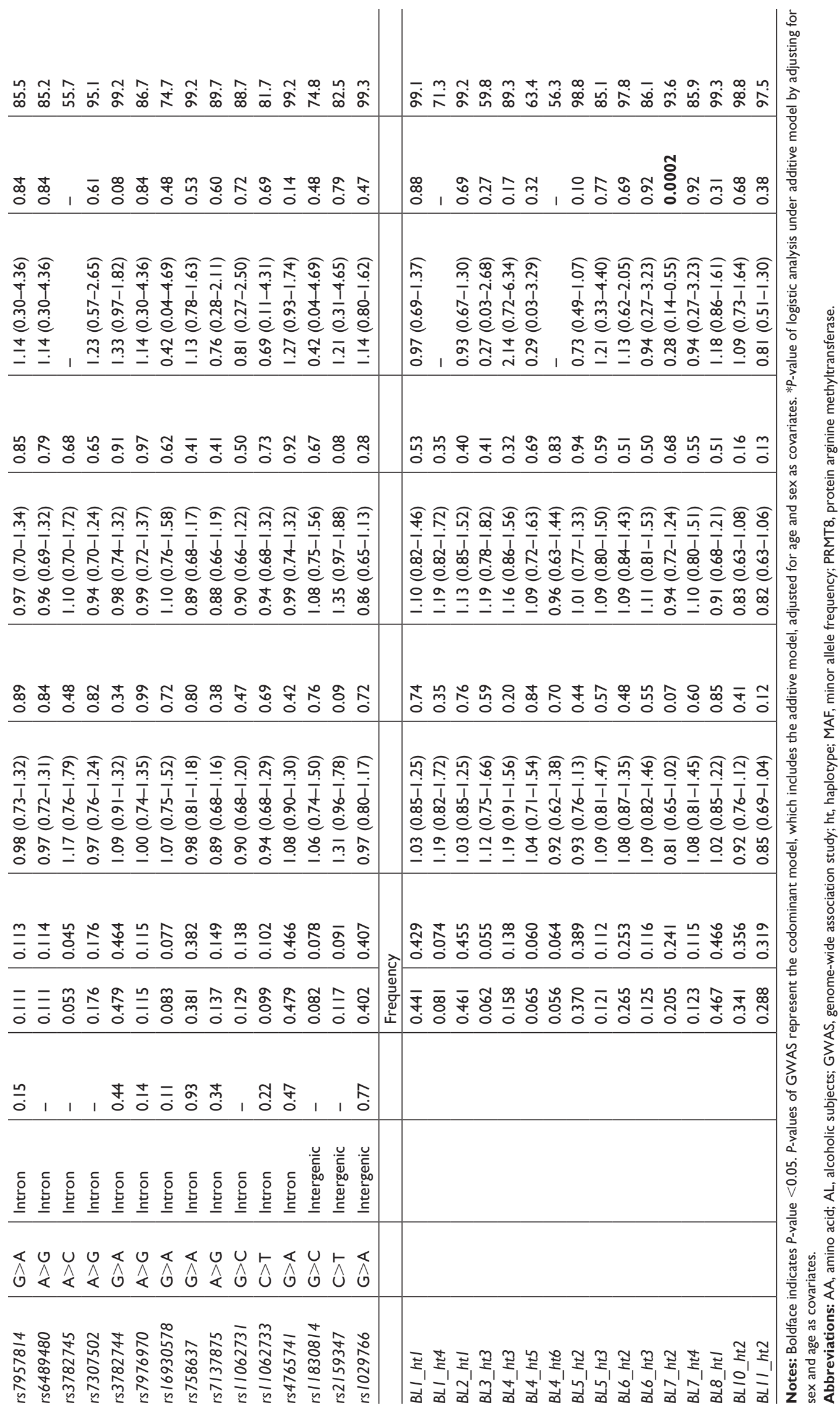


Table S2 Association analysis of PRMT8 SNPs with the AUDIT score in all study subjects $(\mathrm{n}=9 \mid 4)$

\begin{tabular}{|c|c|c|c|c|c|c|c|c|}
\hline \multirow[t]{2}{*}{ Category } & \multirow[t]{2}{*}{ Loci } & \multicolumn{2}{|c|}{$\mathrm{C} / \mathrm{C}$} & \multicolumn{2}{|c|}{$\mathbf{C} / \mathbf{R}$} & \multicolumn{2}{|c|}{$\mathbf{R} / \mathbf{R}$} & \multirow[t]{2}{*}{$P$-value* } \\
\hline & & $\mathbf{N}$ & AUDIT score & $\mathbf{N}$ & AUDIT score & $\mathbf{N}$ & AUDIT score & \\
\hline \multirow[t]{3}{*}{ AUDIT all } & rs4766/38 & 572 & $18.77 \pm 11.79$ & 296 & $|8.20 \pm| 1.81$ & 46 & $12.65 \pm 12.10$ & 0.01 \\
\hline & rs4766139 & 562 & $18.75 \pm 11.79$ & 303 & $18.36 \pm 11.82$ & 49 & $|2.33 \pm| \mid .80$ & 0.01 \\
\hline & $r s / 258 / 829$ & 711 & $18.81 \pm 11.76$ & 183 & $16.34 \pm \mid 2.01$ & 19 & $16.21 \pm 13.06$ & 0.008 \\
\hline \multirow[t]{3}{*}{ Alcohol consumption } & rs $4766 / 38$ & 572 & $8.12 \pm 3.58$ & 296 & $7.98 \pm 3.6 I$ & 46 & $6.48 \pm 4.25$ & 0.04 \\
\hline & rs4766/39 & 562 & $8.12 \pm 3.58$ & 303 & $8.0 I \pm 3.6 I$ & 49 & $6.43 \pm 4.13$ & 0.03 \\
\hline & $r s / 258 / 829$ & 711 & $8.13 \pm 3.56$ & 183 & $7.45 \pm 3.88$ & 19 & $7.74 \pm 3.86$ & 0.03 \\
\hline \multirow[t]{3}{*}{ Alcohol dependence } & $r s 4766138$ & 572 & $4.31 \pm 4.10$ & 296 & $4.21 \pm 4.02$ & 46 & $2.74 \pm 3.87$ & 0.08 \\
\hline & $r s 4766139$ & 562 & $4.28 \pm 4.09$ & 303 & $4.30 \pm 4.05$ & 49 & $2.59 \pm 3.80$ & 0.09 \\
\hline & $r s / 258 / 829$ & 711 & $4.30 \pm 4.08$ & 183 & $3.83 \pm 4.03$ & 19 & $3.53 \pm 4.36$ & 0.09 \\
\hline \multirow[t]{3}{*}{ Alcohol-related harm } & rs4766/38 & 572 & $6.34 \pm 5.22$ & 296 & $6.02 \pm 5.21$ & 46 & $3.43 \pm 4.96$ & 0.005 \\
\hline & $r s 4766 / 39$ & 562 & $6.35 \pm 5.23$ & 303 & $6.06 \pm 5.20$ & 49 & $3.31 \pm 4.86$ & 0.003 \\
\hline & $r s / 258 / 829$ & 711 & $6.38 \pm 5.23$ & 183 & $5.07 \pm 5.11$ & 19 & $4.95 \pm 5.7 \mid$ & 0.001 \\
\hline
\end{tabular}

Notes: $C / C, C / R$, and R/R mean major homozygote, heterozygote, and minor homozygote, respectively. AUDIT score is mean $\pm S D$. $* P$-value of linear regression analysis under additive model by adjusting for sex and age as covariates. Boldface indicates $P$-value $<0.05$.

Abbreviations: AUDIT, Alcohol Use Disorders Identification Test; PRMT8, protein arginine methyltransferase.

\section{Publish your work in this journal}

Neuropsychiatric Disease and Treatment is an international, peerreviewed journal of clinical therapeutics and pharmacology focusing on concise rapid reporting of clinical or pre-clinical studies on a range of neuropsychiatric and neurological disorders. This journal is indexed on PubMed Central, the 'PsycINFO' database and CAS, and is the official journal of The International Neuropsychiatric Association (INA). The manuscript management system is completely online and includes a very quick and fair peer-review system, which is all easy to use. Visit http://www.dovepress.com/testimonials.php to read real quotes from published authors. 